\section{Disintegrative syndrome in young adults}

Editor - I would like to bring to the attention of the professional community, a previously unclassified ICD-10 disorder which occurs in the Down syndrome (DS) population Young Adults with a Disintegrative Syndrome (YADS). As part of the West Midlands health study in DS, 357 adults have been seen over a 10 year period. A significant minority of young adults between the ages of 15 and 30 years with a peak age of approximately 22 years of age present with a specific regressive/disintergative disorder.

The disorder presents with gradual but severe deterioration in function after a normal period of development for an individual with DS. There is marked regression and loss of previously acquired skills in the areas of cognition, expressive and receptive language, mobility, adaptive skills and social skills.

There are frequently associated changes in personality, behaviour and mood where the person may become mute, withdrawn, have reduced social interaction, decrease interests and activities, and present with mild or moderately severe low mood.

Individuals with this disorder may present with features generally observed in later life of dementia of Alzheimer's type. $^{2}$

The change occurs over a period of one to two years but then plateaus with no on-going deterioration (as seen in dementia). Carers become quite concerned regarding the deterioration and seek professional help. Often individuals are not referred for a psychiatric assessment until the 'plateau phase' is reached.

No precise cause is found and extensive investigations (including blood screen, EEG, brain scan) do not reveal a treatable organic cause.

Individuals do not usually fulfil diagnostic criteria for a mental disorder (eg. depression or dementia) but are often treated with a course of anti-depressants where there may be some improvement but there is ongoing residual symptomatology of cognitive, behavioural and social deterioration, but the mood may become euthymic.

YADS is uncommon but appears to occur in a significant number of young DS adults and for any given individual has a major impact on their lives and their carers' lives. The underlying cause of YADS remains to be determined but may be related to:

- The beginnings of deposition of amyloid plaques and neurofibrillary tangles which lead to neuronal dysfunction

- Psychodynamic reaction to leaving long term education and child services which are usually well supported and moving into adult services, where there is a relative deficiency in service.

- Psychological response to development of a self-identity crisis and the awareness of difference with other peers.

Professionals working with people with learning disabilities must be aware of YADS. It is recommended that this disorder becomes the focus of further intensive research and clinical interest.

Vee Prasher,
Associate Professor, Monyhull Hospital,
Monyhull Hall Road, Kings Norton,
Birmingham, B30 3QQ

England

\section{References}

1. World Health Organisation (1992). The ICD-10 Classification of Mental and Behavioural Disorders. Clinical Descriptions and Diagnostic Guidelines. Geneva: WHO. 2. Berg JM, Karlinsky H, Holiand AJ. (1993). Alzheimer disease, Down syndrome, and their relationship. Oxford University Press, Oxford.

\section{Louis Wain and Asperger's syndrome}

Editor - I read with great interest the superb paper by Aidan McGennis on Louis Wain: His life, his art, and his mental illness.'

Louis Wain did not have schizophrenia but Asperger's syndrome. It is very easy to confuse somebody with odd beliefs with schizophrenia and to think that these odd beliefs are formal thought disorder. He did not show deterioration in his skill as a painter and this remained with him towards the end of his life. McGennis is correct to point out this.

There is absolutely no evidence that "his pictures show a visual representation of the progression of his schizophrenia".

Patricia Addridge, curator of the art and history collection at the Bethlehem Royal Hospital has demonstrated clearly that this so called progression is false. There is little doubt that he was a very eccentric if brilliant artist. He was also interested in mathematics, insects, bird skins, perceptual motion, science, and mechanical objects.

He was mostly a withdrawn isolated man from early life. He was bullied in school as many people with Asperger's syndrome are. He spoke with an unusual tone of voice. He had preservation of sameness. He was interested in music and was very obsessional.

He was very naive. He did go through a paranoid psychotic period just like Isaac Newton but the fundamental diagnosis was Asperger's syndrome. ${ }^{3}$

In adult psychiatry Asperger's syndrome is very commonly confused with schizophrenia.

Michael Fitzgerald,
Henry Marsh Professor Child and
Adolescent Psychiatry,
Trinity College,
Dublin 2.
Ireland

References

1. McGennis A. Louis Wain: His life, his art, and his mental illness. Ir J Psych Med, 1999, 16 (1): 27-8.

2: Aldridge P. Cats - an exhibition of the works of Louis Wain $1860-1939$, London Chris Beetles Ltd., 1986: 8-10.

3: Fitzgerald M. Did Isaac Newton have Asperger's syndrome? European Child and Adolescent Psychiatry Journal, 1999, 8, 204. 